\title{
Avaliação económica de tarifas de água no uso agrícola: um estudo de caso no Sul de Portugal ${ }^{1}$
}

\author{
Rui Fragoso ${ }^{2}$ \\ Carlos Marques $^{3}$
}

Resumo: Este artigo avalia os efeitos de políticas de tarifas da água no uso agrícola, em termos do consumo de água, do aproveitamento das áreas beneficiadas com regadio, do rendimento do produtor agrícola, da recuperação dos custos com a água e do desenvolvimento agrícola. A metodologia utilizada baseia-se na elaboração de um modelo de programação matemática multiperíodo, adaptado às características específicas de uma empresa agrícola do Sul de Portugal. Foram analisadas a tarifa fixa por área beneficiada, a tarifa volumétrica por metro cúbico de água consumida, a tarifa binómica e a tarifa progressiva. Para as simulações, foram considerados um cenário produtivo tradicional e um cenário produtivo alternativo, em que são introduzidas culturas de valor acrescentado.

Palavras-chaves: programação multiperíodo, Alentejo, tarifas de água, regadio, risco.

Abstract: This paper evaluates the effects of water tariffs in irrigation, in terms of water consumption, land irrigated, farm income, water cost recovery and agricultural investment. The methodology is based on a multiperiod mathematical programming model, which was applied to the specific characteristics of a representative farm in southern Portugal. The main aspects analyzed were: the fix tariff per area benefited, the volumetric

\footnotetext{
${ }^{1}$ Trata-se de um artigo cujo autores são de Portugal. Dessa forma, o artigo está escrito em português corrente utilizado em Portugal, em que não há correspondência de termos com o português utilizado no Brasil, mesmo para textos científicos em economia.

2 Professor Auxiliar do Departamento de Gestão de Empresas, Universidade de Évora, Portugal. E-mail: rfragoso@uevora.pt

${ }^{3}$ Professor Catedrático do Departamento de Gestão de Empresas, Universidade de Évora, Portugal. E-mail: cmarques@uevora.pt
} 
tariff per cubic meter of water consumed, the mix tariff and the increasing block tariff. For the simulations, it was considered a traditional productive scenario and an alternative scenario, which include value added crops.

Key-words: multiperiod programming, Alentejo, water tariffs, irrigation, risk.

Classificação JEL: Q10, Q25, C61.

\section{Introdução}

Na segunda metade do século $X X$, para garantir o fornecimento de água às populações, a realização de projectos de irrigação e a produção de energia hidro-eléctrica, foi frequente a construção de grandes obras hidráulicas. No entanto, apesar do êxito desse modelo de desenvolvimento, os impactos no ciclo hidrológico foram devastadores, nomeadamente, em termos da qualidade da água e do crescimento da procura, o que tornou, em muitas as regiões do mundo, a água num bem escasso. Face esta situação, desde o final do século XX que se assiste a uma mudança de paradigma na política de gestão da água. A tradicional política de fomento hidráulico está a dar lugar ao controle da eficiência e da procura da água, sendo crescente a introdução de critérios económicos, como os preços públicos ou tarifas de água e os mercados de água (GLEICK, 2000).

Neste contexto, o sector agrícola desempenha um papel de grande importância, devido ao facto de ser o maior consumidor de água do planeta e devido à eficiência de a utilização ser baixa. Segundo González-Romero e Rubio (1993), um incremento de 10\% na eficiência da utilização agrícola da água corresponde a uma poupança equivalente ao volume de água consumido em todo o mundo no uso urbano.

Em muitos países que se deparam com problemas de falta de água, um dos instrumentos frequentemente utilizados são os preços públicos ou tarifas de água na agricultura (WILCHENS, 1991; CUMMINGS e NERCISSIANTZ, 1992; ROSEGRANT at al., 1995). Na União Européia, são vários os países que já utilizam estes instrumentos de gestão da água na agricultura, nomeadamente a França (MONTGINUOL, 1997). Na Espanha, Varela-Ortega et al. (1998) discutem a aplicação de diferentes tipos de tarifas de águas em vários regadios do país. Em Portugal, a aprovação da Directiva Quadro da Água (2000/60/CE) pela União Européia, que estabelece um quadro de acção comum na União Européia para a protecção das águas, abre perspectivas para a aplicação de preços públicos ou tarifas de água, que promovam simultaneamente a utilização eficiente do recurso e a recuperação dos custos da oferta de água.

Em algumas regiões do Brasil, nomeadamente, no Nordeste e na bacia do Rio de São Francisco, com o clima semi-árido, os problemas da gestão da água na 
agricultura apresentam algumas semelhanças com os que se assiste em Portugal, caracterizando-se principalmente pela escassez de água na estação estival e pela necessidade de promover o uso eficiente do recurso e garantir o financiamento da oferta de água por meio de um sistema de tarifas de água adequado. No Brasil, a aprovação da Lei Federal da Água em janeiro de 1997, constituiu uma mudança de paradigma na gestão da água no País, na medida em foi introduzida uma ampla reforma no sector da água, incluindo o estabelecimento de preços da água por grosso (bulk water prices).

A aplicação das disposições da Lei Federal da Água, especialmente em matéria de preços da água, foi diferenciada nos vários estados brasileiros, tendo sido no Ceará onde foi mais efectiva. O Ceará foi o pioneiro na aplicação de uma política de preço da água por grosso, principalmente por se tratar de um estado em que a água é escassa, por não haver produção de energia hidro-eléctrica - e, como tal, ausência de receitas por esta via para custear a operação e a manutenção das infra-estruturas -, por haver uma marcada escassez sazonal de água e por a estratégia de desenvolvimento deste estado se basear num agressivo programa de industrialização e de turismo à escala internacional (ASAD et al., 1999).

No Brasil, são vários os estudos que tratam as questões do preço da água no retalho, entre estes, destaca-se: Godin Filho (1992), Lanna (1994), Lanna (1995), Pinheiro e Shirota (2000). No entanto, com excepção do último, esses estudos limitam-se a determinar a tarifa que permite cobrir os custos de operação e manutenção dos sistemas de suprimento de água destinada à irrigação. O estudo de Pinheiro e Shirota (2000), traduz um contributo adicional, na medida em que também determina os preços e as quantidades de água a afectar a diferentes culturas num perímetro de rega do Ceará.

No caso de Portugal, Fragoso (2004), Noéme et al. (2004) e Avillez et al. (2004) realizaram vários ensaios sobre o preço da água na agricultura do Sul do país, com o objectivo de determinar a disponibilidade a pagar pela água e os seus efeitos na afectação das culturas, nos rendimentos agrícolas e na recuperação dos custos da oferta. Tanto para o Brasil quanto para Portugal, contudo, nenhum autor faz a avaliação económica de diferentes tipos de tarifas no uso agrícola.

Face à pertinência do tema, este artigo tem como objectivo avaliar os efeitos económicos da adopção de diferentes tipos de tarifas de água no uso agrícola, em termos do consumo de água, do aproveitamento da superfície regada, do rendimento agrícola, da recuperação dos custos com a oferta de água e do investimento agrícola. O estudo é aplicado a uma empresa agrícola representativa do perímetro de rega público de Odivelas, na Região Alentejo, no Sul de Portugal. A metodologia utilizada baseia-se no desenvolvimento de um modelo de programação matemática multiperíodo.

Além desta introdução, este artigo é composto por mais quatro partes, que compreendem algumas notas sobre os fundamentos de uma política de tarifas, a metodologia utilizada, os resultados e as conclusões. 


\section{Os fundamentos de uma política de tarifas de água}

No âmbito da Directiva Quadro da Água (DQA) pretende-se incentivar pela via do preço da água o uso sustentável do recurso, imputando os custos aos utilizadores. Nestes, merecem destaque os custos de exploração e de manutenção e os custos ambientais associados às actividades, havendo alguma flexibilidade quanto à internalização dos custos de investimento.

Na perspectiva da DQA, a política de gestão da água deve promover a eficiência e ter em conta a equidade no acesso ao recurso. A eficiência do uso da água depende da minimização dos desperdícios e da afectação óptima do recurso, devendo o uso da água aproximar-se o mais possível da fronteira eficiente de produção e o valor da produtividade marginal igualar o seu custo marginal nos diferentes usos (BOWEN e YOUNG, 1986; FRAGOSO, 2001; HENRIQUES et al, 2006). A equidade traduz-se na igualdade do acesso à água e na redistribuição dos rendimentos gerados pela água a favor dos agricultores com menos recursos (BARR, 1992; PEARCE, 1986). A política de gestão da água deverá também considerar nos seus objectivos a recuperação dos custos com a água. No entanto, é frequente que o equilíbrio orçamental da oferta seja incompatível com os objectivos de eficiência e de equidade, devido aos rendimentos crescentes e à escala do monopólio natural em que se processa a oferta de água.

Em Portugal, nos perímetros de rega públicos, como é o caso de Odivelas (objecto deste estudo), o monopólio natural é constituído pelo Estado, que delega algumas responsabilidades nas associações de beneficiários, que se constituem como entidades privadas. O Estado é o responsável pela concepção, construção e financiamento das infra-estruturas de irrigação e afectação da água no domínio público hídrico, cabendo às associações de beneficiários a gestão, operação e manutenção dessas infra-estruturas.

A nova Lei da Água (Lei no58/2005) transpõe para a legislação portuguesa a DQA e actualiza o regime económico e financeiro em vigor no Decrecto Lei n⿳0口269/82 de 10 de junho. Estabelece-se, assim, as bases de um quadro institucional para a gestão sustentável da água, em que, no caso dos perímetros de rega do Estado, as associações de beneficiários devem restituir ao Estado as receitas da taxa de recursos hídricos, entendida como o preço da água no grosso, e fixar e cobrar aos agricultores tarifas de água, que não são mais do que preços da água no retalho.

Deste modo, as associações de beneficiários devem conceber um sistema de tarifas de água para os agricultores que promovam o uso sustentável da água e que, simultaneamente, cubram os custos com a oferta de água. Estes custos compreendem, os custos de exploração da estrutura e dos serviços da associação de beneficiários, os custos de operação, de manutenção e de capital das infra-estruturas de irrigação. Relativamente, aos custos de capital referentes aos 
reservatórios e aos canais primários e secundários de rega, tem existido alguma flexibilidade por parte do Estado na restituição das verbas correspondentes.

A política tarifária é um instrumento de regulação económica da procura de água que, por meio da modificação dos preços ou da transferência de rendimentos, tenta influenciar as decisões dos agricultores, de modo a que estes alterem voluntariamente o seu comportamento (BARDE, 1993). As políticas tarifárias tiveram inicialmente como principal objectivo a recuperação dos custos com a água. No entanto, com o aumento da escassez do recurso, tornaram-se progressivamente num instrumento de afectação eficiente.

A teoria microeconómica neoclássica constitui o fundamento teórico da política tarifária, podendo estabelecer-se tanto do lado da oferta como do lado da procura. Na óptica da procura, a afectação óptima do recurso é dada pelo valor da produtividade marginal e pela competição entre os diferentes usos. No uso agrícola, a procura da água é derivada e depende dos preços dos produtos nos mercados agrícolas, da produtividade marginal da água na função de produção agrícola e da competição entre as culturas de regadio disponíveis. Na óptica da oferta, as tarifas de água devem tentar cobrir os custos com os serviços de abastecimento, os custos de escassez relacionados com o uso do recurso, os custos integrais da oferta e os custos sociais, como os decorrentes da poluição. A grande questão da política tarifária reside na fixação do nível da tarifa e na adopção de uma tarifa ao custo marginal ou ao custo médio.

A tarifa ao custo marginal conduz à maximização do bem-estar social e fornece um sinal da escassez do recurso aos seus utilizadores, induzindo, por conseguinte, à eficiência económica. A maximização do bem-estar social só é possível se todos os sectores tarifarem a água ao custo marginal. No entanto, quando existem rendimentos crescentes a escala, há sectores que deixam de aplicar a tarifa ao custo marginal (MONNIER, 1983). Nos grandes regadios, em que o preço da água cobrado é inferior ao seu custo médio de obtenção, o equilíbrio entre a oferta e a procura ocorre na parte convexa da função de produção da água. Por essa razão, a adopção de uma tarifa ao custo marginal conduz ao déficit orçamental da oferta. Outro aspecto que limita a aplicação da tarifa ao custo marginal é a necessidade de se dispor de informação detalhada (OCDE, 1987).

A tarifa ao custo médio é o instrumento adequado para a recuperação dos custos com a água e, por conseguinte, para resolver o problema orçamental da oferta (WINPENNY, 1994). O seu principal pressuposto reside numa procura inelástica da água, sendo, por isso, reduzida a sua influência sobre a procura. Para além de não considerar os aspectos sazonais e de longo prazo na procura, este tipo de tarifa água não conduz a uma maximização do bem-estar. 


\section{Metodologia}

A metodologia utilizada, para fazer a avaliação económica de tarifas de água no uso agrícola, baseia-se num modelo de programação matemática multiperíodo, desenvolvido para uma empresa agrícola representativa do Sul de Portugal, a partir dos trabalhos de Blanco (1996), Godinho (1997) e Henriques (1995).

Este modelo determina a combinação óptima de actividades de produção vegetal de regadio (cereais, oleaginosas e pastagens e forragens, hortofrutícolas e industriais e frutuiras) e de sequeiro (cereais, oleaginosas e pastagens e forragens) e de actividades de produção pecuária (bovinos de corte), em função da maximização do valor actualizado líquido dos activos do produtor, da minimização do risco de produção e de mercado e da probabilidade de ocorrência de uma determinada dotação de água. Todas as decisões de investimento (máquinas e equipamentos, plantações e animais reprodutores) e de financiamento (capital próprio e capital alheio) são tomadas em função das decisões de produção.

Em resposta a eventuais alterações, como a política de tarifas de água, o modelo prevê: i) a substituição entre culturas de regadio; ii) a substituição de culturas de regadio por culturas de sequeiro; e iii) a substituição entre culturas de sequeiro; e iv) o abandono da actividade agrícola.

As principais variáveis de decisão $\left(X_{j}\right)$ e $\left(Y_{I}\right)$ são as actividades de produção vegetal (ha) e de produção pecuária $(\mathrm{CN})$ e as actividades de investimento em maquinaria agrícola (h ou $\mathrm{n}^{-}$), equipamentos de rega (ha), plantações (ha) e em efectivos pecuários $(\mathrm{CN})$. A formulação simplificada deste modelo é dada pelas seguintes expressões:

$$
\begin{aligned}
& \text { MaxU }=Z-p h i \cdot \sum_{t=1}^{n} \frac{\sigma_{t}}{(1+t a)^{t}} \\
& Z=\sum_{t=1}^{n} \frac{C S_{t}+P P_{t}+A L-R E}{(1+t a)^{t}} \\
& C S_{t}=0,6 . C F_{t} \\
& I M O_{t}=0,4 \cdot C F_{t} \\
& I M O_{t}=C P_{t}+P P_{t} \\
& A L=P v_{I} \cdot\left(b_{1, t}+Y_{1, t-d}+Y_{1, t}\right) \\
& R E=\sum_{t=n-d}^{n} E P L_{t}-\sum_{t=n-d}^{n} E L P_{t} \cdot a n n+E C P_{n} \\
& \sigma_{t}=\sqrt{\sum_{y=1}^{Y} \frac{\left(C F_{t}-C F_{t, y}\right)^{2}}{y}}
\end{aligned}
$$


s.a.

$$
\begin{aligned}
& C F_{t}=C F_{j, t}+S D_{t-1}+E C P_{t}-(1+i) \cdot E C P_{t-1}-\text { ann. } E L P_{t-d}-S D_{t} \\
& S D_{t-1}+E C P_{t} \geq D E_{j, t} \cdot X_{j, t}+(1+i) \cdot E C P_{t}+\text { ann.ELP } P_{t-d} \\
& C P_{t}+E C P_{t} \geq P_{I} \cdot Y_{I, t}-s b_{I, t} \\
& \sum_{j} a_{j} \cdot X_{j, t} \leq b_{I, t}+Y_{I, t-d}+Y_{I, t} \\
& \sum_{j} a_{j} \cdot X_{j, t} \geq q_{t}=Q_{t} \cdot h \\
& \sum_{j p f} q a_{j p f, y, p} \cdot X_{j p f, t} \geq \sum_{j e} q a_{j e, p} \cdot X_{j e, t} \\
& \sum_{j} X_{j, t} \leq S
\end{aligned}
$$

em que, $t=1,2, \ldots 10$ são os períodos do horizonte de planificação (anos); e ta é a taxa real de actualização.

A equação (1) traduz a maximização do valor actualizado dos activos líquidos do produtor $(Z)$ e a minimização do risco $(\sigma)$.

O valor actualizado dos activos líquidos é dado pela soma actualizada do consumo do produtor (CS), com as poupanças acumuladas $(P P)$ e com o valor final dos activos $\left(A L_{n}\right)$, depois de deduzido o valor actual dos empréstimos que faltam liquidar no final do horizonte temporal $\left(R E_{n}\right)$. De acordo com Henriques (1995), o consumo anual do produtor foi fixado em $60 \%$ do cash-flow anual $\left(C F_{t}\right)$, sendo os restantes $40 \%$ imobilização de capital $\left(I M O_{t}\right)$ destinada à poupança $\left(P P_{t}\right)$ e ao financiamento do investimento $\left(C P_{t}\right)$.

O risco na função objectivo é medido por meio do desvio padrão dos cash-flow anuais da empresa $\left(\sigma_{t}\right)$ e do grau de aversão ao risco do produtor (phi), tendo em conta a existência de 15 estados de natureza $(y), 3$ relativos às condições de mercado e 5 relativos às condições técnicas e agro-climáticas da produção vegetal. $\mathrm{O}$ desvio padrão do cash-flow anual é calculado pela diferença entre o valor médio $\left(C F_{t}\right)$ e o valor em cada estado de natureza $\left(C F_{t, y}\right)$.

Na equação (2), é calculado o cash-flow anual da empresa, tendo em conta o cash-flow das actividades produtivas $\left(C F_{t, j}\right)$, os empréstimos de curto prazo $\left(E C P_{t}\right)$, as transferências de fundos do período anterior $\left(S D_{t-1}\right)$, o serviço de dívida, calculado em função da taxa de juro $i$ dos empréstimos de curto prazo e da anuidade (ann) dos empréstimos de longo prazo, e o fundo de maneio do período seguinte $\left(S D_{t}\right)$.

As equações (3) e (4) estabelecem, respectivamente, as condições de liquidez da empresa e de financiamento do investimento. Para a liquidez, impõe-se que as 
despesas correntes das actividades produtivas $\left(D E_{j, t}\right)$ mais os montantes do serviço de dívida sejam inferiores ao total das transferências de fundos do período anterior e dos empréstimos de curto prazo. $\mathrm{O}$ valor do investimento $\left(P_{I}, Y_{I, t}\right)$ é financiado por capitais próprios resultantes da imobilização de capital $\left(C P_{t}\right)$, por empréstimos de longo prazo $\left(E L P_{t}\right)$ e por subsídios a fundo perdido $\left(s b_{I, t}\right)$.

A equação (5) modela em cada período do horizonte de planificação o uso dos recursos e os investimentos, garantindo que as necessidades das actividades produtivas nesses recursos $\left(a_{j}\right)$ não excedem a disponibilidade inicial $\left(b_{I, t}\right)$ mais a capacidade instalada no período $\left(Y_{I, t}\right)$ e em períodos anteriores $\left(Y_{I, t-t-d}\right)$. Devido à sazonalidade das operações agrícolas, o modelo considera, também, o uso e a contratação de mão-de-obra por período do calendário agrícola.

A equação (6) restringe o consumo de água do plano de produção $\left(q_{t}\right)$ à dotação de água bruta $Q$ fornecida pela associação de beneficiários da obra de rega de Odivelas, depois de deduzidas das perdas $h$ na rede secundária. A dotação $Q$ corresponde a um volume de água que é variável entre anos, em função das condições meteorológicas e da garantia do sistema de abastecimento para satisfazer a procura em cada período. Deste modo, a disponibilidade de água é formulada por meio da restrição probabilística:

$$
\operatorname{Pr}\left\{\frac{1}{h} \sum_{j} q_{j} X_{j, t} \leq Q_{t}\right\} \geq 1-\alpha
$$

Esta restrição, indica que a dotação $Q$ se verifica com uma probabilidade de ocorrência $\alpha$. Assumindo que os coeficientes estocásticos seguem uma distribuição normal, $Q$ pode ser expresso em função da esperança matemática $(E(Q))$, do desvio padrão da distribuição $\left(\sigma_{Q}\right)$ e de uma constante que depende da probabilidade de ocorrência $\alpha\left(k_{\alpha}\right)$ :

$$
E(Q)-k_{\alpha} \cdot \sigma_{Q}
$$

Este método, utilizado por Sumpsi et al. (1998), consiste em considerar a dotação $Q$ inferior à dotação esperada $E(Q)$ numa magnitude de $k_{\alpha} . \sigma_{Q}$. Neste estudo, considerou-se um valor de $\alpha$ de $52 \%$, que coincide com a frequência relativa com que ocorre a dotação observada no perímetro de rega de Odivelas. A utilização de uma estrutura estocástica que permitisse ajustar as estratégias do produtor em cada estado de natureza de disponibilidade de água seria mais adequada (FRAGOSO, 1996 e 2001). No entanto, a sua aplicação conduziria a um problema de programação estocástica dinâmica, o que acresceria substancialmente a complexidade da análise.

O balanço forrageiro é estabelecido por meio da equação (7), que é desdobrada nas equações de balanço de energia metabolizável, de proteína bruta e de capacidade máxima de ingestão dos animais. Estas equações, para captar a 
variabilidade e a sazonalidade da produção de pastagens, são estabelecidas por estado de natureza de produção $(y)$ e por período crítico do crescimento de pastagens $(p)$. Garante-se, assim, que as necessidades $\left(q a_{j e, p}\right)$ energéticas e protéicas dos animais são satisfeitas e que a sua capacidade máxima de ingestão não é excedida. A variabilidade da produção forrageira $\left(q a_{j p f, y, p}\right)$ implica a aquisição de alimentos ao exterior em maior ou menor extensão.

A equação (8) garante que a área das culturas não excede a área disponível, ou que a área das culturas de regadio é inferior à área irrigável. Para além destas restrições estruturais de uso da terra, o modelo inclui restrições que decorrem das rotações praticadas, da imposição de quotas de produção e de dificuldades de comercialização.

\section{Resultados}

Antes de ser utilizado como instrumento prospectivo, o modelo foi testado para diferentes níveis de aversão ao risco. Este procedimento permitiu validar o modelo e fixar o valor do coeficiente de aversão ao risco (phi) mais aderente à realidade observada.

Para avaliar os efeitos económicos das políticas de tarifas de água, consideram-se 4 tipos de tarifas: a tarifa fixa (TF) por área beneficiada ( $€ /$ ha); a tarifa proporcional ou volumétrica (TV) por metro cúbico de água consumida $\left(€ / \mathrm{m}^{3}\right)$; a tarifa binómica (TB), que resulta da combinação das duas anteriores (€/ha e $\left.€ / \mathrm{m}^{3}\right)$; e a tarifa progressiva (TP) por patamares crescentes de consumo $\left(€ / \mathrm{m}^{3}\right)$.

Partindo do nível da tarifa actual simularam-se, para cada tipo de tarifa, 10 níveis crescentes em $30 \%$ cada um. As simulações foram efectuadas para o cenário da PAC de 2003, considerando o perfil produtivo tradicional (cereais, oleaginosas, beterraba, pastagens e forragens e carne de bovino) e o perfil produtivo alternativo, que, para além das opções produtivas do perfil produtivo tradicional, introduz culturas de valor acrescentado dos sub-sectores das horto-frutícolas e industriais (tomate, melão, pimento, cebola e batata) e das fruteiras (macieiras, pereiras, uva de mesa, ameixieiras e pessegueiros).

No cenário produtivo tradicional, para a tarifa inicial $\left(0,017 € / \mathrm{m}^{3}\right)$, o consumo de água é idêntico à dotação disponível $(8170$ m³/ha) nas simulações TV, TB e TF. No caso da TP, o consumo inicial de água é de apenas $5450 \mathrm{~m}^{3} / \mathrm{ha}$, o que reflecte para o mesmo custo médio da tarifa uma redução no consumo de $33 \%$. Para induzir este nível de consumo seria necessário elevar o custo médio da tarifa nas três simulações anteriores acima de 0,022, de 0,029 e de 0,049 €/ $\mathrm{m}^{3}$, respectivamente (Gráfico 1 ).

No cenário produtivo alternativo as curvas da procura da água são mais inelásticas do que as obtidas para o cenário produtivo tradicional. Para a tarifa inicial, o consumo de água é igual à dotação disponível em todas as simulações. 
Com as TV, TB e TP, obtêm-se reduções significativas no consumo de água (60 a $70 \%$ ), quando o custo médio da tarifa é de $0,063 € / \mathrm{m}^{3}$, i.e., quando as curvas da procura se tornam mais elásticas. No caso da TF, o aumento da tarifa não tem qualquer impacto sobre o consumo, confirmando-se a inadequação deste tipo de tarifa na indução do uso eficiente da água de rega (Gráfico 2).

Gráfico 1. Consumo de água no cenário produtivo tradicional.
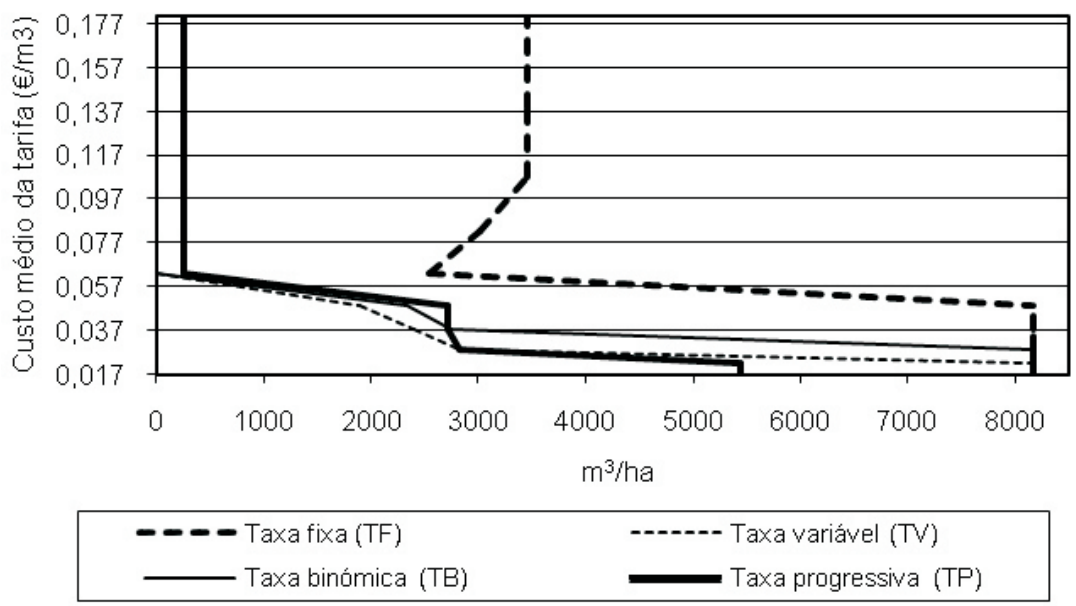

Fonte: Resultados do modelo de programação matemática.

Gráfico 2. Consumo de água no cenário produtivo alternativo.
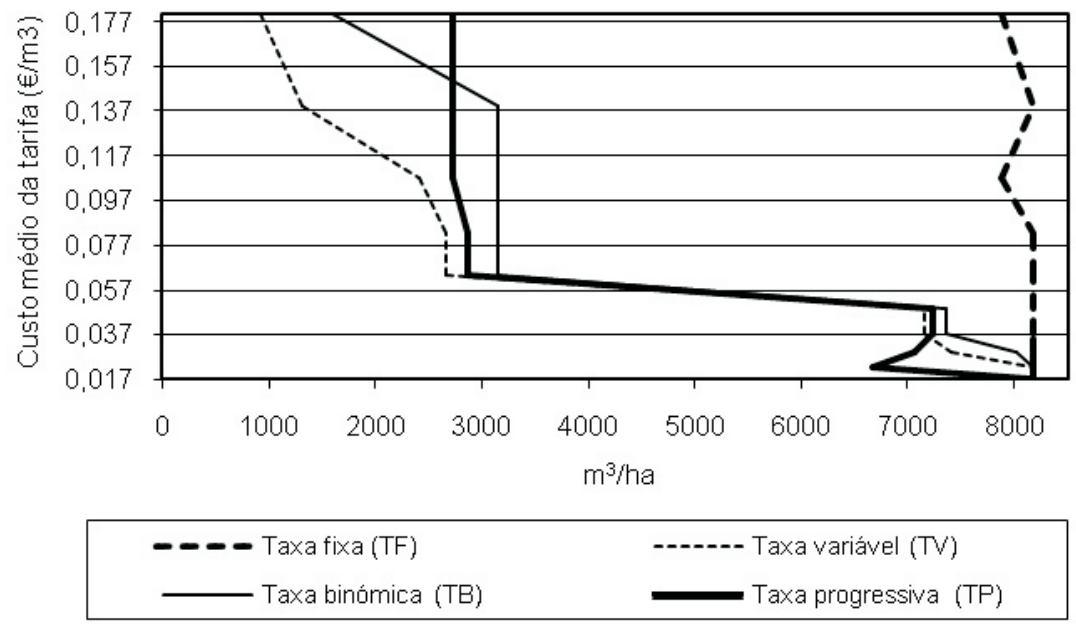

Fonte: Resultados do modelo de programação matemática. 
Do pondo de vista da utilização eficiente do recurso, a TP é a que permite obter os melhores resultados. A TV e com a TB, apesar de conduzirem a resultados inferiores, também induzem significativamente ao uso eficiente da água. A TF é a que proporciona os resultados piores em termos da afectação eficiente da água de rega.

No cenário produtivo tradicional, a taxa de utilização do regadio para o nível inicial da tarifa nas simulações das TF, TV e TB representa $18,4 \%$ da SAU, que é o limite máximo da superfície irrigável. Quando se considera a TP, a taxa de utilização do regadio é pouco mais de $10 \%$ da SAU. Na TV, na TB e na TP, a taxa de utilização do regadio baixa para $50 \%$ quando o custo médio da tarifa atinge os $0,037 € / \mathrm{m}^{3}$ e é nula para valores acima de $0,063 € / \mathrm{m}^{3}$. No caso da $\mathrm{TF}$, apesar de os efeitos do aumento da tarifa serem menores do que nas restantes simulações, para um custo médio da tarifa de $0,063 € / \mathrm{m}^{3}$ a taxa de utilização do regadio é apenas 3\% (Gráfico 3).

Gráfico 3. Superfície regada no cenário produtivo tradicional.

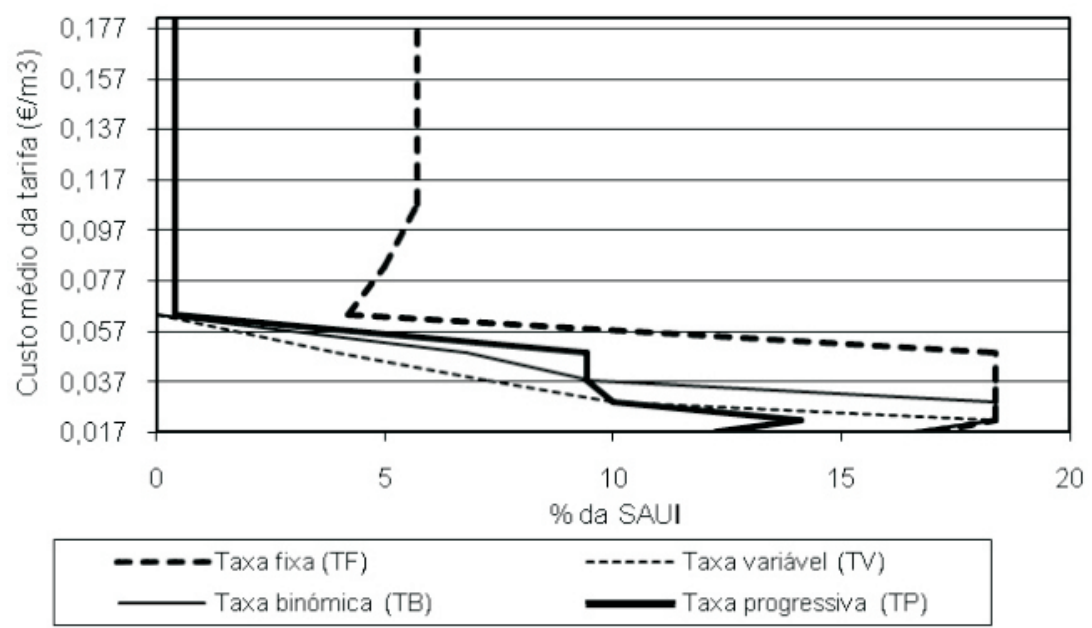

Fonte: Resultados do modelo de programação matemática.

No cenário produtivo alternativo, há também uma relação directa entre a diminuição do consumo e da superfície regada. Nas simulações TV, TB e TP a superfície regada é aproveitada na totalidade para níveis de custo médio da tarifa até $0,049 € / \mathrm{m}^{3}$. A partir desse nível a taxa de utilização do regadio baixa dos $18,4 \%$ iniciais para ligeiramente menos da metade (Gráfico 4). 
Gráfico 4. Superfície regada no cenário produtivo alternativo.

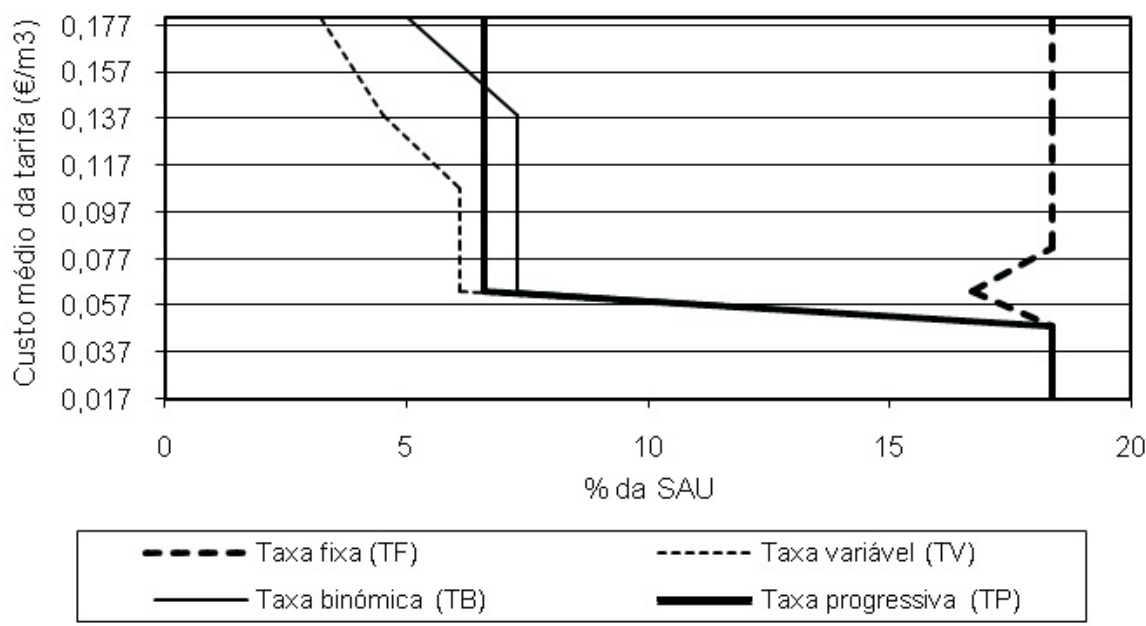

Fonte: Resultados do modelo de programação matemática.

Os melhores resultados em termos do aproveitamento da superfície regada obtêm-se com a TF, que não tem influência directa no consumo de água, sendo a TP a que mais penaliza o aproveitamento do regadio.

A amplitude da diminuição dos rendimentos dos produtores agrícolas decorrente do aumento do custo da água depende da elasticidade da procura da água, das estratégicas de redução de consumo adoptadas e, no caso das tarifas variáveis em função do consumo, também da dotação inicial. As perdas de rendimento de maior amplitude ocorrem nos segmentos mais inelásticos da curva da procura da água, quando o aumento percentual do custo médio da água é superior à diminuição percentual do consumo.

No cenário produtivo tradicional, um aumento inicial do custo médio da tarifa de $30 \%$ leva em todas as simulações a uma perda de rendimento quase da mesma amplitude. A comparação das tarifas simuladas, mostra que, para um custo médio inferior a $0,063 € / \mathrm{m}^{3}$, a TF e a TP são as que menos penalizam o rendimento, sendo a TV e a TB as mais prejudiciais. Para níveis superiores, a TF é a que provoca as maiores perdas de rendimento (Gráfico 5). 
Gráfico 5. Rendimento agrícola no cenário produtivo tradicional.

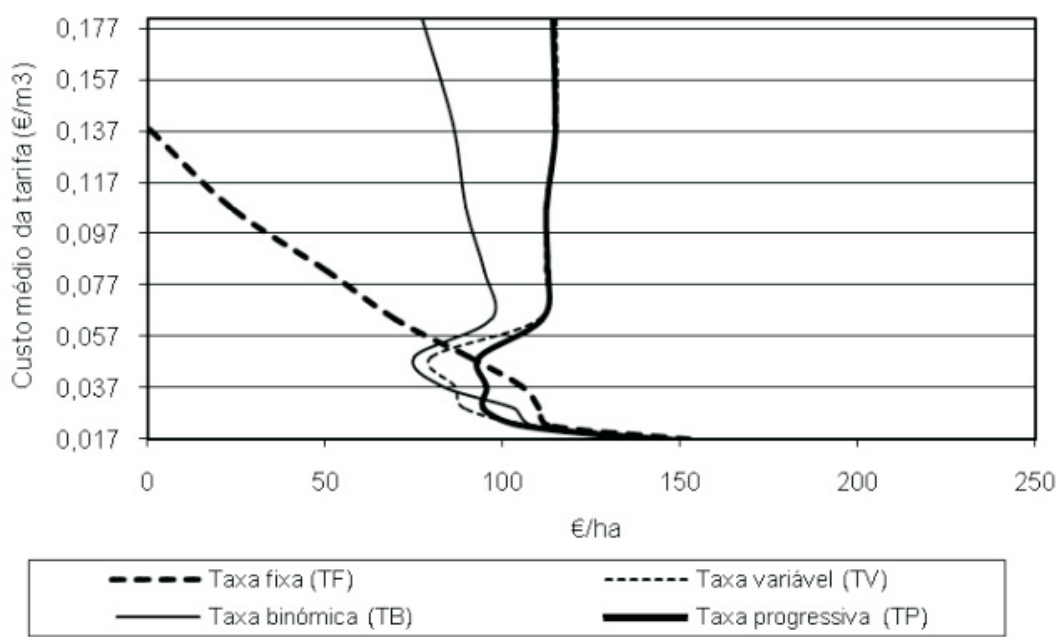

Fonte: Resultados do modelo de programação matemática.

No cenário produtivo alternativo, o peso dos custos com água nas receitas é relativamente reduzido sendo, por isso, menor o efeito da política de tarifas no rendimento do que no cenário produtivo tradicional. Um aumento da tarifa inicial de 30\% provoca apenas reduções marginais no rendimento nas TV, TB e TP e de $15 \%$ na TF (Gráfico 6).

Gráfico 6. Rendimento agrícola no cenário produtivo alternativo.
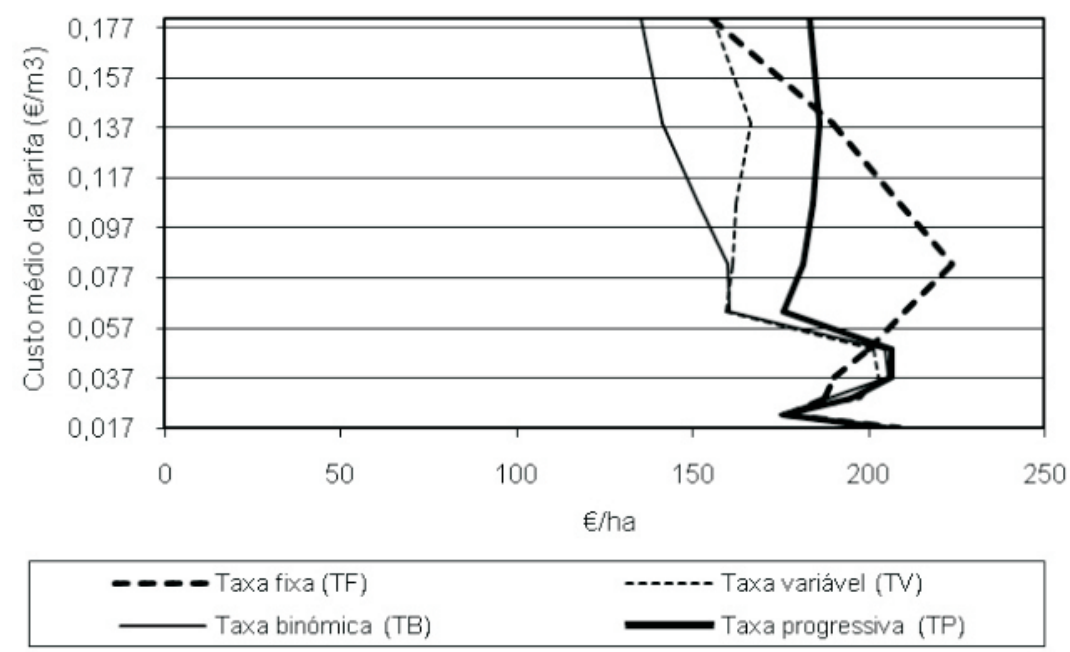

Fonte: Resultados do modelo de programação matemática. 
No cenário produtivo tradicional, a recuperação dos custos com a água para a tarifa inicial é de $139 € /$ ha com as TF, TV e TB e de $70 € /$ ha com a TP. Um aumento do custo médio da tarifa de $0,017 € / \mathrm{m}^{3}$ para $0,022 € / \mathrm{m}^{3}$ permite subir esses valores água para $182 € /$ ha nas três primeiras simulações e para $91 € /$ ha na TP. Nos casos da TV e da TP, para níveis superiores de custo médio da tarifa, a recuperação dos custos com a água desce (Gráfico 7).

Gráfico 7. Recuperação dos custos com a água no cenário produtivo tradicional.
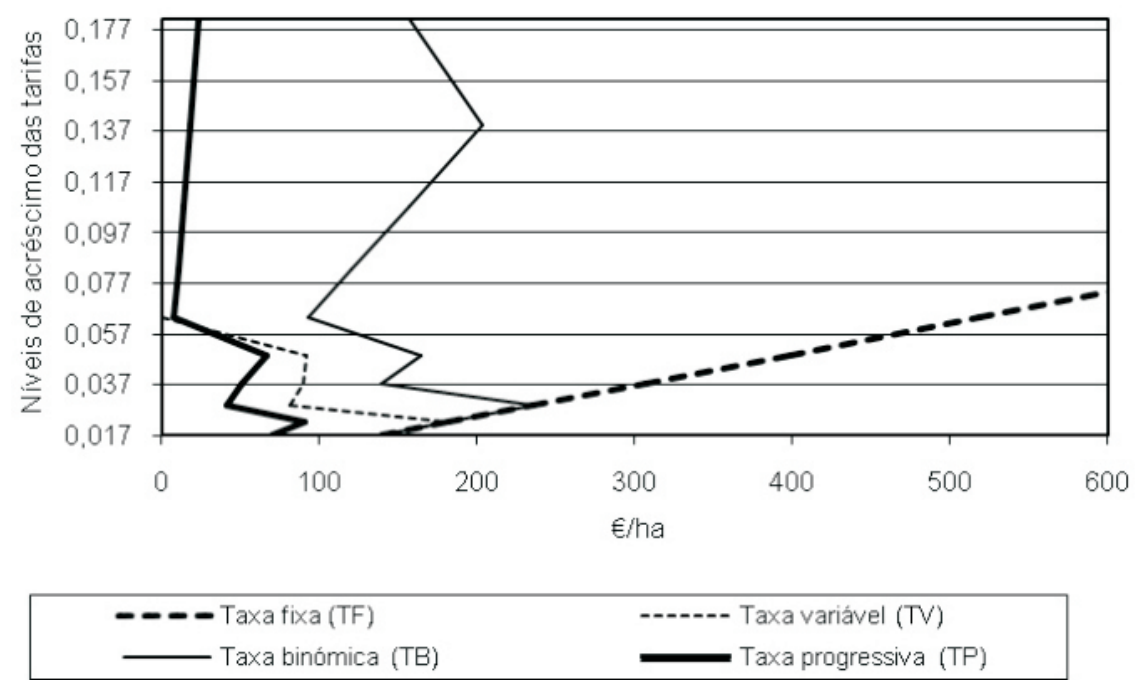

Fonte: Resultados do modelo de programação matemática.

No cenário produtivo alternativo, como a procura da água é mais inelástica, a recuperação dos custos melhora significativamente nos casos da TV, da TB e da $\mathrm{TP}$, aumentando dos $139 € /$ ha iniciais até cerca de $350 € /$ ha, quando o custo médio da tarifa atinge $0,049 € / \mathrm{m}^{3}$. A partir deste nível de custo médio, a recuperação dos custos com água diminui significativamente com a TV e com a TP (Gráfico 8). 
Gráfico 8. Recuperação dos custos com a água no cenário produtivo alternativo.

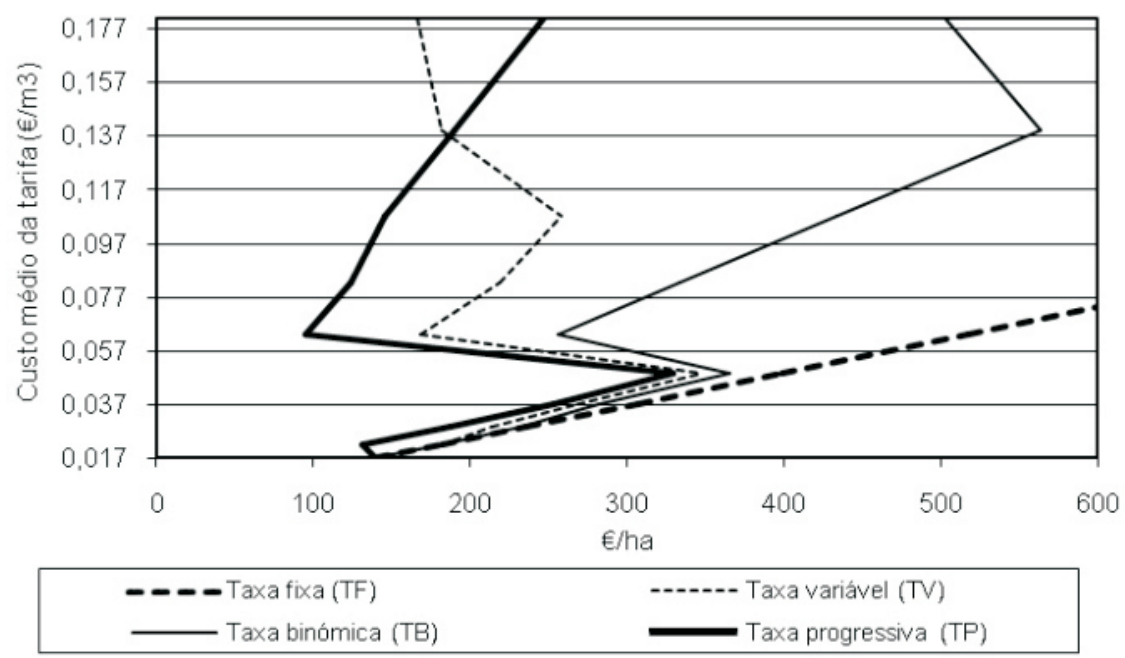

Fonte: Resultados do modelo de programação matemática.

Noéme et al. (2004) estimaram para o perímetro de rega de Odivelas um custo médio de $479 € /$ ha de área beneficiada, dos quais $322 € /$ ha dizem respeito aos custos anualizados do investimento público e, os restantes $157 € /$ ha, aos custos de exploração e conservação. Estes montantes só são recuperáveis na totalidade com a adopção da TF e para um custo médio da tarifa de $0,063 € / \mathrm{m}^{3}$. Com as restantes tarifas simuladas recuperaram-se, no cenário produtivo tradicional, os custos de exploração e de conservação, com um custo médio da tarifa de $0,022 € / \mathrm{m}^{3}$ e, no cenário produtivo alternativo, os custos de exploração e conservação e cerca de $60 \%$ dos custos do investimento nas infra-estruturas, quando o custo médio da tarifa é $0,049 € / \mathrm{m}^{3}$ (350 €/ha).

A TF é a que permite obter os melhores níveis de recuperação dos custos com água, aumentando progressivamente com o incremento do nível da tarifa. A seguir surge a TB, sendo a TV e a TP as que menos contribuem para o equilíbrio orçamental na oferta.

O efeito das tarifas de água simuladas em termos do investimento agrícola foi analisado por meio do Valor Actualizado Líquido (VAL).

No cenário produtivo tradicional, o VAL obtido com as TV, TB e TP é superior a $1000 € /$ ha, sendo os valores do investimento agrícola de 1416 a 1760 €/ha. No caso da TF esses valores são, respectivamente, $661 € /$ ha e $4057 € /$ ha. Com a adopção do perfil produtivo alternativo, os valores desses indicadores aumentam substancialmente - o VAL quase que triplica no caso da TF e sobe $50 \%$ nos casos das TV, TB e TP. No que diz respeito ao investimento agrícola, os acréscimos são, respectivamente, de 11\%,79\%,72\% e 47\% (Tabela 1). 
Tabela 1. Indicadores de desenvolvimento agrícola.

\begin{tabular}{lcccc}
\hline & $\begin{array}{c}\text { Tarifa fixa } \\
(\text { TF) }\end{array}$ & $\begin{array}{c}\text { Tarifa } \\
\text { variável } \\
\text { (TV) }\end{array}$ & $\begin{array}{c}\text { Tarifa } \\
\text { binómica } \\
\text { (TB) }\end{array}$ & $\begin{array}{c}\text { Tarifa } \\
\text { progressiva } \\
\text { (TP) }\end{array}$ \\
\hline & Cenário produtivo tradicional \\
Valor actualizado líquido & 661 & 1142 & 1041 & 1153 \\
Investimento & 4057 & 1416 & 1735 & 1760 \\
\hline \multicolumn{5}{c}{ Cenário produtivo alternativo } \\
Valor actualizado líquido & 1737 & 1705 & 1639 & 1798 \\
Investimento & 4513 & 2541 & 2986 & 2584 \\
\hline
\end{tabular}

Fonte: Resultados do modelo de programação matemática.

Apesar, da TP e da TV serem as que proporcionam os melhores níveis de consumo do produtor, o investimento agrícola é mais elevado com a TF e com a TB.

\section{Conclusões}

Este artigo avalia, para uma empresa agrícola representativa do perímetro de rega de Odivelas no Sul de Portugal, os efeitos económicos de diferentes tarifas de água, tendo em conta o cenário produtivo tradicional e em alternativa a introdução de culturas de valor acrescentado. A metodologia utilizada baseia-se num modelo de programação matemática multiperíodo, que determina a combinação óptima das actividades de produção e de investimento agrícola.

Do ponto de vista do uso eficiente da água na agricultura, os melhores resultados obtêm-se com a tarifa progressiva, seguindo-se as tarifas volumétrica e a binómica. A tarifa fixa, por não estar directamente relacionada ao consumo de água, é a que permite o melhor aproveitamento das áreas beneficiadas com regadio. Para as restantes tarifas analisadas, o aproveitamento da área irrigada diminui com a redução do consumo de água. A subida das tarifas de água resulta sempre numa diminuição dos rendimentos agrícolas, registando-se as perdas mais elevadas nos segmentos mais inelásticos das curvas da procura da água.

O equilíbrio orçamental da oferta de água depende da capacidade de recuperar os seus custos, o que se verifica especialmente nos segmentos rígidos das curvas da procura da água. Deste ponto de vista, a tarifa fixa é a preferível, dada que a recuperação dos custos é independente da diminuição do consumo de água. Os restantes tipos de tarifas simuladas permitem recuperar os custos de exploração e conservação, se o custo médio da tarifa aumentar até $0,022 € / \mathrm{m}^{3}$; com a introdução de culturas de valor acrescentado, esse valor aumenta para 0,049 $€ / \mathrm{m}^{3}$, o que permite cobrir os custos de exploração e de conservação e cerca de $60 \%$ dos custos do investimento nas infra-estruturas. 
Em termos do investimento agrícola, a tarifa progressiva e a tarifa volumétrica são as que proporcionam os retornos mais elevados, enquanto que a tarifa fixa e a tarifa binómica privilegiam o investimento e, por conseguinte, a formação bruta de capital.

Este estudo conclui que a tarifa binómica é a que melhor contribui, simultaneamente, para o uso eficiente da água na agricultura e para o equilíbrio orçamental da oferta de água, devendo, por isso, privilegiar-se a sua adopção no perímetro de rega de Odivelas. O valor da sua componente fixa deverá situar-se entre 54,9 e $71,4 € /$ ha e o da sua componente variável, entre 0,031 e $0,040 € / \mathrm{m}^{3}$, o que corresponde a um custo médio entre 0,037 e 0,049 €/ $\mathrm{m}^{3}$. Estes valores são relativamente inferiores aos propostos para o preço da água no novo regadio de Alqueva $\left(0,063\right.$ a $\left.0,09 € / \mathrm{m}^{3}\right)$, que se abastece sob pressão a partir do maior lago artificial da Europa.

Apesar da especificidade da aplicação deste estudo ao perímetro de rega de Odivelas no Sul de Portugal, os principais resultados e conclusões permanecem válidos noutros contextos e corroboram as hipóteses de outros autores. Num estudo aplicado ao projecto de irrigação Curu-Paraipaba no Nordeste do Brasil, Pinheiro e Shirota (2000) também concluíram que, se fosse praticado o preço eficiente da água de irrigação, esta seria afecta principalmente as culturas de valor, o que permitiria aumentar substancialmente o valor bruto da produção e as receitas do governo e, por conseguinte, cobrir, com folga, todos os custos de operação e manutenção.

\section{Referências Bibliográficas}

AVILLEZ, F.; SILVA, F.G.; MARTINS, V. Preço da água e rentabilidade da agricultura de regadio em Portugal: metodologia para cálculo do impacto da Reforma da PAC e da aplicação da Directiva Quadro da Água. In: IV Congresso Nacional de Economistas Agrícolas. Faro, 2004.

ASAD, M.; AZEVEDO, L.; KEMPER, K.; SIMPSON, L. Management of Water Resources: Bulk Water Pricing in Brasil. World Bank Technical Paper, no 432, p. 51. 1999.

BARDE, J.P. Quel instrument choisir face à un problème d'environnement ?. Actes du Colloque INSEE Méthodes, Paris, p. 215-233. 15 et 16 de février 1993.

BARR, N. Economic theory and the welfare state: a survey and interpretation. Jornal of Economic Literature, 30 (2), p. 671-764. 1992. 
BLANCO, M. Analyse des impactes socio-économiques et des effects sur l'environnement des politiques agricoles: modélisation de l'utilisation des ressources en eau das la région espagnole de Castille-León, Montpellier : CIHEAM-IAMM, Collection de Thèses et Masters IAMM, n.o 32. 1996.

BOWEN, R.L.; YOUNG, R.A. Appraising alternatives for allocation and cost recovery for irrigation water in Egypt. Agricultural Economics, 1, p. 35-52. 1996.

CUMMINGS, G.; NERCISSIANTZ, V. The use of water pricing as a means for enhancing water use efficiency in irrigation: Case studies in Mexico and in the United States. Natural Resources, 72, p. 731-755. 1992.

DECRETO-LEI No 269/82. Dário da República Portuguesa 157/82, Série I, 10 de Junho de 1982.

DIRECTIVE 2000/60/EC of the European Parliament and of the Council of 23 October 2000 Establishing a Framework for Community Action in the Field of Water Policy. Official Journal of European Comunities 22.12.2000, L327 p. 1-72. 2000.

FRAGOSO, R.M.S. Évaluation des impacts socio-économiques du développement de l'irrigation: le cas de l'agriculture dans la région de l'Alentejo, Montpellier: CIHEAM-IAMM, Collection de Thèses et Masters IAMM, n.․ 40. 1996.

FRAGOSO, R.M.S. Avaliação dos Impactos Sócio-Económicos de Plano de Rega de Alqueva no Sector Agrícola do Alentejo: o caso do bloco de rega da infra-estrutura 12. Dissertação de Doutoramento - Universidade de Évora, Evvora, 2001.

FRAGOSO, R. Perspectivas Futuras para a Exploração do Aproveitamento Hidro-Agrícola da Vigia Face à Política de Preço da Água. In: IV Congresso Nacional de Economistas Agrícolas. Faro, 2004.

GLEICK, P. The Changing Water Paradigm: A Look at Twenty-first Century Water Resources Development. Water International, vol. 25, nำ1, p. 127-138. 2000.

GODIN FILHO, J. Determinação da tarifa d'água do projecto de irrigação Curu-Paraipaba. Dissertação de Mestrado - Centro de Ciências Agrárias Universidade Federal do Ceará, p. 86, Fortaleza, 1992.

GODINHO, L. The Impact of 1992 CAP Reform on Soil Erosion in the Alentejo Region of Portugal. Ph.D. Dissertation - Wye College, University of London, London, 1997. 
GONZÁlEZ-ROMERO, A.; RUBIO, S. El problema de la Planificación Hidrológica: Una aplicación al caso español. Revista de Economia Aplicada, 1, p.33-66. 1993.

HENRIQUES, P.D.S. Technical Efficiency and Changes in Alentejan Farming Systems. PhD. Dissertation - The University of Reading, Reading, 1995.

HENRIQUES, P.; BRANCO, M.; FRAGOSO, R.; CARVALHO, M.L. Direito ao Acesso à Água: princípios económicos para seu usufruto na agricultura. Évora: em Banco, M, Carvalho, L.S. e Rego, C. et al. (eds.), Economia do Compromisso Ensaios em Memória de José Sena, Universidade de Évora, 29-54, 2006.

LANNA, A. Estudos para cobrança pelo uso da água bruta no Estado do Ceará: simulação tarifária para a bacia do rio Curu. Relatório 2 - COGERH, Fortaleza, 1994.

LANNA, A. Estudos para cobrança pelo uso da água bruta no Estado do Ceará: simulação tarifária para a bacia do rio Curu. Relatório 2A - COGERH, Fortaleza, 1995.

LEI n058/2005. Diário da República Portuguesa 249/2005, Série IA, 29 de Dezembro de 2005.

MONNIER, L. La tarification de l'électricité en France. Economica, Paris, 1983.

MONTGINUOL, M. Une approche economique de la gestion de l'eau d'irrigation: Des intruments, de l'information et des acteurs. Tese de Doutoramento-Faculté dês Sciences Economiques - Université Montpellier I, 1997.

NOÉME, C.; FRAGOSO, R.; COELHO, L. Avaliação económica da utilização da água em Portugal - Determinação do preço da água para fins agrícolas: Aplicação nos Aproveitamentos Hidro-Agrícolas de Odivelas, da Vigia e do Sotavento Algarvio. estudo realizado para o Ministério da Agricultura e do Desenvolvimento Rural, IDRHa, 2004.

NOÉME, C.; FRAGOSO, R. Evaluation of Alternative Policies of Irrigation Water Price. Application to Large Farms in Alentejo Region. Agricultural Engineering International - the CIGR Ejournal, Manunscrip LW 04006, vol VI, December, 2004

OCDE Tarification dês services relatifs à l'eau, Paris, 1987.

PEARCE, D.W. The dictionary of modern economics, EL-BS, Macmillan, 3 ${ }^{\mathbf{a}}$ Edição, Reino Unido. 1986.

PINHEIRO, J.; SHIROTA, R. Determinação do Preço Eficiente da Água para Irrigação no Projecto Curu-Paraipaba. Revista Econômica do Nordeste, v. 31, no1, p. 36-47. 2000. 
ROSEGRANT, M.; SCHELEYER, R.; YADAV, S. Water policy for efficiency agricultural diversification: maket based approaches. Food Policy, 20, p. 203-223. 1995

SUMPSI, J.M.; GARRIDO, A.; BLANCO, M.; VARELA ORTEGA, C.; IGLESIAS, E. Economía et política de gestión del agua en la agricultura, Madrid: (Eds. Mundi-Prensa), Secretaría General Técnica de Desarrollo Rural y Conservación de Naturaleza, MAPA. 1998.

WILCHENS, D. Motivating reduction in drain water with block-rate prices for irrigation water. Water Res. Bull, 27, p. 585-592. 1991.

WINPENNY, J. Managing water as an economic resource. London: Routldge, ODI (Overseas Development Institut), United Kingdom, 1994.

VARELA-ORTEGA, C.; SUMPSI, J.; GARRIDO, A.; BLANCO, M.; IGLEGIAS, E. Water pricing policies, public decision making and farmers' response: implication for water policy. Agricultural Economics, 19, p. 193-202. 1998. 